\title{
A domain-specific account of self-regulated learning: the cognitive and metacognitive activities involved in learning through historical inquiry
}

\author{
Eric G. Poitras • Susanne P. Lajoie
}

Received: 21 June 2012 / Accepted: 24 September 2013 /

Published online: 3 October 2013

(C) Springer Science+Business Media New York 2013

\begin{abstract}
Educational researchers have recently begun to conceptualize theoretical constructs and mechanisms of metacognitive activities in terms of the features that are specific to particular academic domains and subject matter. In this paper, we propose a framework of domain-specific metacognition in relation to learning through historical inquiry. The framework postulates that students' comprehension of historical events is mediated by a state of coherence in understanding the causes that explain why an event occurred. Comprehension breaks down when the causes that explain the occurrence of historical events are unknown, uncertain, or unreported. In order to reinstate coherence in understanding, students engage in cognitive and metacognitive activities in accordance with disciplinary-based practices. Drawing on the existing empirical evidence, we discuss how the study of self-regulatory processes contributes to our understanding of the challenges faced by students while learning about complex historical topics as well as the skills that are required to gain knowledge while investigating the past.
\end{abstract}

Keywords Metacognition $\cdot$ Self-regulated learning $\cdot$ Domain-specific $\cdot$ History education

\section{Introduction}

Thinking about one's thinking, or metacognition (Flavell 1976), is central to learning in that we learn to monitor what we know and do not know. Learners learn to recognize impasses and errors and then use strategies to gain control over their understanding or performance during a task. Constructs pertaining to self-regulation (Baker and Brown 1984) and selfregulated learning (SRL) (Corno and Mandinach 1983; Zimmerman 1989) grew out of the early theories of metacognition to study the role of these basic processes in learning in

Electronic supplementary material The online version of this article (doi:10.1007/s11409-013-9104-9) contains supplementary material, which is available to authorized users.

E. G. Poitras $(\bowtie) \cdot$ S. P. Lajoie $(\bowtie)$

Department of Educational and Counselling Psychology, McGill University, Education Building, 3700 McTavish St., Montreal, QC H3A 1Y2, Canada

e-mail: eric.poitras@mcgill.ca

e-mail: susanne.lajoie@mcgill.ca 
academic domains and have become increasingly more sophisticated in their frameworks (see Butler and Winne 1995; Pintrich 2000, 2004; Schunk 2005; Winne 2001; Winne and Hadwin 1998, 2008; Winne and Perry 2000; Zimmerman 2000, 2006, 2008). However, there is still a lack of consensus in regards to the definition of these theoretical constructs in the educational literature (Dinsmore et al. 2008; Veenman et al. 2006).

Patricia Alexander and her colleagues recently called for researchers to study whether there are distinct differences in SRL across domains (Alexander et al. 2011). The underlying premise for this claim is that different domains, such as history and mathematics for instance, differ with respect to the nature of instructional tasks and the structure of their subject matter, which influences how students regulate their own learning. In support of their claim, Alexander and colleagues conducted a review of the literature and found that there is a paucity of empirical research that simultaneously examined SRL across multiple domains. Although the basic sciences were frequently cited as the most prevalent domain under SRL investigation, there may be important differences in the tasks, contents, and strategies involved within and between domains that may not be accounted for by existing models of SRL.

In this paper, we examine the assumption of domain-specificity with respect to the field of history, an emerging area of study within the SRL literature. In doing so, we first distinguish between several tasks that are performed (i.e., text-studying vs. problemsolving) across different domains (i.e., history, physics, biology, and so on). The CMHI model characterizes self-regulation in solving problems within the domain of history. More specifically, the model explains how learners monitor, set goals, and control certain aspects of their learning while performing lines of inquiries into the causes of historical events. In doing so, we outline the three-phase model of cognitive and metacognitive activities in historical inquiry (CMHI). The CMHI model illustrates the domain-specific properties of SRL by synthesizing theoretical frameworks of historical reasoning and problem-solving (Carretero et al. 1997; Nokes et al. 2007; van Drie and van Boxtel 2008) with the Information Processing Theory (IPT) of SRL in text-studying (Winne 2001, 2005; Winne and Hadwin 1998, 2008, 2010). In doing so, we argue that the basic tenets of SRL theories are applicable across tasks and domains. The characterization of SRL as a constituent structure that incorporates superordinate (i.e., metacognitive activities) and subordinate constructs (i.e., cognitive activities) transcends inherent differences across tasks and domains. The CMHI model of SRL supports this claim as an application of the Information Processing Theory of SRL to the domain of history and the task of problem-solving. In both models of SRL, the activation of assemblies of subordinate constructs is explained in terms of a production system of self-instructions. However, the characterization of SRL in terms of domain- or task-specific constructs contributes to the educational literature by highlighting novel areas for scientific research and educational interventions. In support of this claim, we will show how the CMHI model of SRL can help account for the onset of historical reasoning, capture specific aspects of the trajectory towards competency in the domain of history and assist with instructional challenges in this domain.

The assumption of domain-specificity in self-regulated learning

Dinsmore and his colleagues (2008) reviewed the educational literature with the aim of describing how the terms metacognition, self-regulation, and self-regulated learning have been defined. The term metacognition was first introduced by Brown (1978) and Flavell (1976). Metacognition was gained through experience and consisted of knowledge of oneself, the task at hand, and the strategies that are helpful to monitor and control one's performance on the task. Metacognitive knowledge was described in terms of belief systems 
(Flavell 1976), relevant task conditions (Schraw and Moshman 1995), as well as declarative and procedural knowledge (Kuhn 1999).

Metacognitive activities reflect the strategic application of metacognitive knowledge in order to monitor and control the cognitive processes that mediate learning (Veenman 2011, 2012). Meijer et al. (2006) developed an extensive taxonomy of metacognitive activities used in studying historical texts by contrasting those activities in solving physics problems. The taxonomy is organized as a hierarchy with 6 superordinate constructs and 70 subordinate categories. The superordinate constructs consist of orientation, planning, execution, monitoring, evaluation, and reflection. Subordinate activities occur in sequence of discrete events as in the case where learners search for information in texts by looking for particular information, selecting pieces of text, and then judging whether the information was found or not. The reading goal is accomplished unless the information was not found and the learner has to repeat the search process.

Metacognitive activities are in some instances limited to specific domains, such as science, history, mathematics, and so on (Schraw 2006; Shanahan 2009; Van der Stel and Veenman 2010; Veenman et al. 2006). Meijer and colleagues (2006) found that although $60 \%$ of the categories in their taxonomy of metacognitive activities were applicable to both the physics and history task, there were differences inherent to the domain and task that mediated the use of metacognitive activities. For instance, planning activities such as organizing thoughts by questioning oneself was found in both the physics and history tasks. However, students gave meaning to axes of graphs, and setting up a coordinate system when solving physics problems, while students studying historical texts read difficult parts of the texts again and consulted their notes.

Although the existing models of SRL differ in terms of the choice of constructs and processes that characterize the metacognitive activities (Azevedo 2009; Efklides 2008, 2009; Fox and Riconscente 2008; Metcalfe 2009; Schraw 2006; Zimmerman and Schunk 2011), these models share several basic assumptions (see Pintrich 2000; Zimmerman 2001). First, learners are actively involved in making sense of information from their internal cognitive system and external environment. Second, learning occurs in phases, such as planning, monitoring, control, and evaluation, wherein learners' focus on different issues including cognition, motivation/affect, behaviour, and the context/environment. Third, different conditions that are inherent to the situation and learner constrain regulatory activities during learning. Fourth, learning involves setting goals, comparing outcomes against standards, and using strategies to control relevant aspects of cognitions, motivations, behaviours, and the context. In doing so, self-regulated learners possess a wide range of knowledge regarding obstacles to learning as well as the skills that are necessary to address them. Fifth, learners' ability to regulate certain aspects of cognitions, motivations, behaviours, and the context during task performance mediates learning outcomes. As such, SRL theories conceptualize learning as a complex system of activities that are iterative and adaptive, wherein cognitive, metacognitive, motivational, and contextual components interact (Butler and Winne 1995; Pintrich 2000, 2004; Schunk 2005; Winne 2001; Winne and Hadwin 1998, 2008; Winne and Perry 2000; Zimmerman 2000, 2006, 2008).

There is a paucity of evidence in relation to how SRL might differ in a given domain, such as history, and whether it is due to task differences, including text-studying and problem-solving. Available evidence obtained from a single empirical study using the IPT model of SRL suggests that students face significant challenges in regulating certain aspects of their learning while studying historical texts (Greene et al. 2010). Students engage less often in planning and monitoring activities, even though planning was found to predict gains in declarative knowledge. Moreover, students relied most often on SRL strategies such as summarization and taking notes as opposed to elaborations and making inferences, despite the fact that these strategies were not found to predict learning outcomes. 
As such, current models of SRL are limited in terms of explaining how disciplinary-based practices are involved in regulating certain aspects of learning (see Alexander et al. 2011; Meijer et al. 2006; Veenman et al. 2004). Although current SRL theories acknowledge that strategies operate differently depending on the nature of the topic that is studied (Pintrich et al. 1991, 1993; Winne et al. 2002; Winne and Perry 2000) there is little discussion of specific differences between task characteristics. This stands in contrast with other areas of research that differentiate the elements of models on the basis of subject domain, for instance in achievement emotions (Goetz et al. 2010) and motivation (Zanobini and Usai 2002; Bong 2001). As we will show in this paper, SRL theories can explain how a learner is able to regulate processes involved in solving historical problems in accordance with disciplinarybased practices. In the next section, we outline the basic assumptions that underlie the components and processes of the CMHI model, which provides a domain-specific account of SRL in the discipline of history.

A domain-specific model of self-regulated learning in history

We developed the CMHI model of SRL based on our attempts to clarify and expand the domain-specificity assumption of SRL. In doing so, we synthesized theoretical constructs from models of SRL (Winne 2001, 2005; Winne and Hadwin 1998, 2008, 2010) and historical reasoning (Carretero et al. 1997; Nokes et al. 2007; van Drie and van Boxtel 2008). There are several basic assumptions that underlie domain-specific accounts of SRL, which are also shared with domain-general models. The first assumption is that several aspects of self-regulated learning are particular to certain disciplines (Alexander et al. 2011). The CMHI model accounts for how task conditions, cognitive resources, and motivation constrain learners' attempts to regulate the cognitive and metacognitive activities involved in learning about history. The second assumption is that learners regulate their learning through an iterative and adaptive process wherein cognitive and metacognitive activities interact with each other (Winne 2001, 2005; Winne and Hadwin 1998, 2008, 2010). The CMHI model states that several cognitive states (i.e., conditions, standards, outcomes, goals, and strategies) underlie the metacognitive processes (i.e., monitoring, goalsetting, and controlling) that are involved in learning. The third assumption is that learning occurs in the context of performing authentic tasks in the relevant discipline (van Drie and van Boxtel 2008). As such, the CMHI model conceptualizes learning as performing inquiries into the causes of historical events.

The CMHI model of SRL characterizes cognition, metacognition, and regulation in terms of the order of processing. The lowest order processes are cognitive activities. These activities refer to the basic strategies that are involved in processing information, such as elaborating, storing, and recalling information (Neisser 1967). On the next level are metacognitive activities, which pertain to procedural knowledge about how to monitor and strategically control cognitive processes that are involved in learning (Veenman 2005, 2011, 2012; Veenman et al. 2006). The highest order processes are regulatory activities. These activities involve the coordination of goal-setting, monitoring, and controlling activities in an iterative, adaptive, and purposeful manner (Boekaerts et al. 2000; Pintrich 2000; Zimmerman 2000, 2001; Zimmerman and Schunk 2011). The term activity is thus used to describe specific aspects of the different processes that are occurring as part of this hierarchy. These fundamental SRL components account for the regulation of learning through the coordination of relevant variables (i.e., aspect of cognition, behaviour, motivation, affect, context), phases (e.g., before learning: task definition, forethought; vs. after learning: reflection, modifications), and constraints (i.e., developmental and contextual). 
The model concurs with other research in conceptualizing information processing as an acquired production system of self-instructions for the regulation of learning (Veenman 2011; Winne 2010; Winne and Hadwin 2008). An if-then statement is used to represent each selfinstruction as a conditional rule, whereby if a certain condition is present, then this will result in a given action. As an example, one of the self-instructions that are hypothesized by the CMHI model is if you notice that the causes of an historical event are unknown, then set a goal to argue in favour of the most likely cause. A complete list of the self-instructions that are postulated by the CMHI model is included in the Appendix. As such, self-instructions are modelled in a manner similar to conditional knowledge - knowledge about when procedures should be used (Schraw and Moshman 1995; Schraw 2006). Cognitive activities are involved in the execution of self-instructions, while metacognitive activities have an executive function, as they are involved in initiating cognitive activities in response to information about states that characterize the cognitive system. This production system of self-instructions determines how the learner makes adaptations during learning by making progress in an iterative and purposeful manner. The CMHI model of SRL represents this production system of self-instructions in terms of constructs, processes, and phases, as shown in Fig. 1.

Learning results from the inquiry process, which is regulated by the learner in consecutive phases wherein progress is made in understanding why an event occurred. The first phase of the CMHI model states that learners engage in regulatory activities when task conditions are problematic such as when historical documents fail to mention cause(s) that lead to the occurrence of an event. Under these conditions, learners' understanding of why an event occurred is incoherent (i.e., the causes are unknown). Phase two occurs when learners engage in regulatory activities to reinstate coherence in understanding. If a learner notices that a document fails to explain why an event occurred, the learner may investigate further. In performing inquiries into the causes of an historical event, one assumes that the learner lacks prior knowledge in regards to the event, has sufficient motivation and interest, and possesses the necessary procedural knowledge about disciplinary-based practices. Procedural knowledge consists of knowledge in relation to strategies, including how to ask appropriate questions, formulate explanations, use concepts, evaluate the trustworthiness of sources, as well as to gather, corroborate, and contextualize evidence. In order to attain the goal, a learner applies knowledge in relation to these strategies in an iterative and weakly sequenced manner, and as a result, becomes progressively more certain about the most important causes for the event. Phase three pertains to evaluating the outcomes of these investigations. Learners judge whether their understanding of the causes for the event is coherent or not. As a result, a learner may choose to pursue learning about the same topic, explore diverse topics, or cease learning entirely. In the following sections, we define each construct and explain how these constructs are interrelated within the processes and phases that constitute the CMHI model of SRL.

\section{The characterization of metacognitive activities in the CMHI model of SRL}

We now turn to the description of monitoring, control, and goal-setting activities in the context of historical inquiry and how such activities are constrained by cognitive resources and task conditions. In doing so, we describe the interactions between these metacognitive activities, their relationship to cognitive activities, and their impacts on the different phases of learning.

Cognitive resources and task conditions refer to the characteristics of the task performed by a learner and the available resources that mediate learning. Task conditions constrain learning by defining the time requirements for the task, the sources of information that are available, as well as the details and nature of the information mentioned in each source. Cognitive resources are made available during learning, when a learner draws on familiarity 


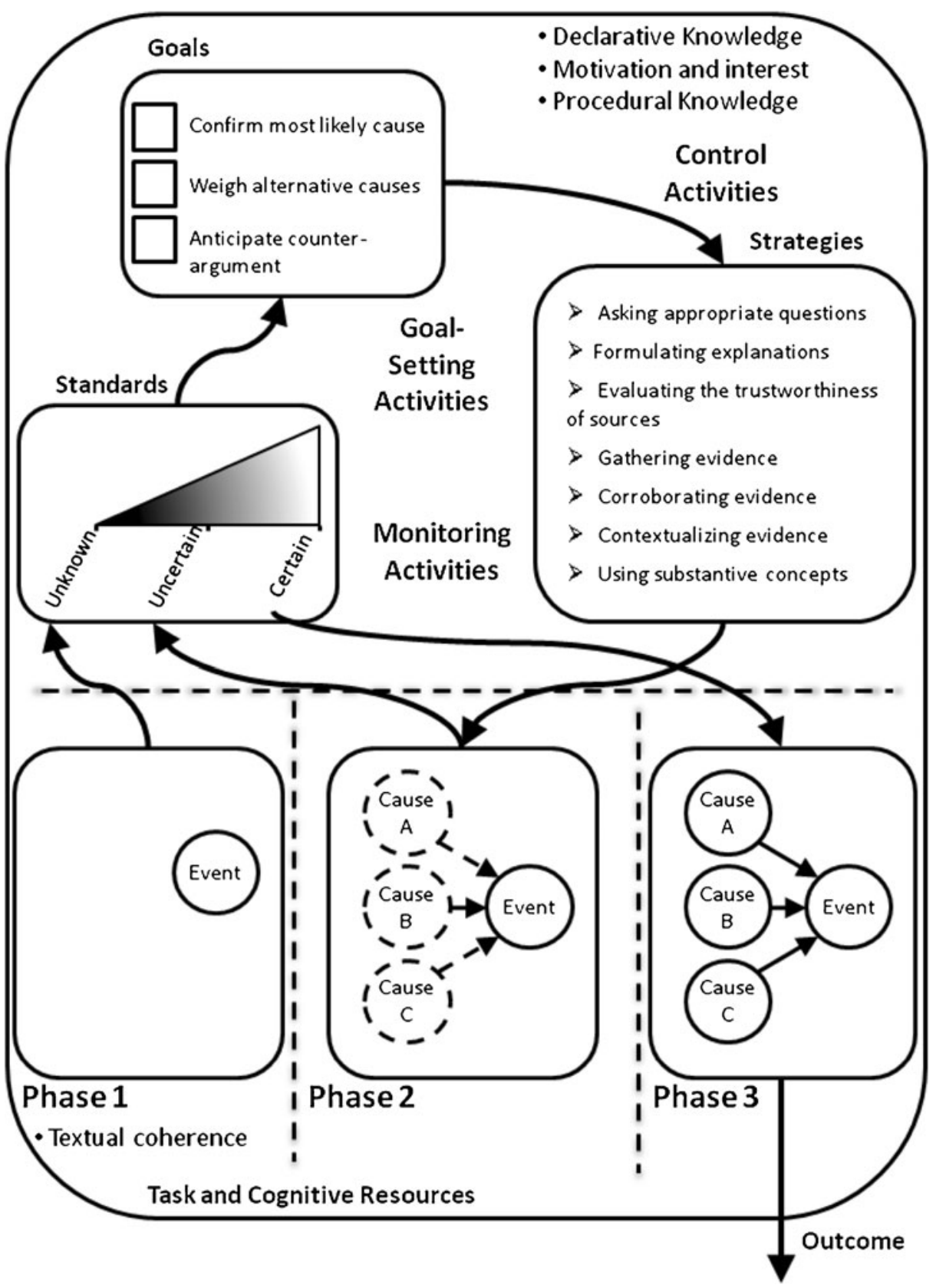

Fig. 1 The three-phase model of Cognitive and Metacognitive activities in learning through Historical Inquiry (CMHI)

and interest in relation to the topic of the document, relevant prior knowledge in regards to the time period, and prior experience in historiographical practices (i.e., methodology of historical research). The CMHI model postulates that task conditions and cognitive resources interact with the cognitive and metacognitive activities that mediate learning. For 
instance, the causes of any particular historical event may not be reported in the circumstances described in an historical narrative text (see Poitras et al. 2012a) that might create an obstacle to understanding why the event occurred. Learners require the prerequisite cognitive resources to formulate an historical explanation, and such resources are enhanced by their knowledge of disciplinary-based practices, sufficient motivation and opportunity to find answers.

Monitoring activities occur when a learner compares explanations against standards for causality. Causality is a type of standard or criterion that states that consequent activities should logically follow from their antecedents. Causation constrains learning through the need to organize and interpret information obtained from sources in terms of chains of causes and effects (Halldén 1997, 1998; Jacott et al. 1998; Leinhardt 1997; Voss et al. 1994; Voss and Wiley 1997). Phase one of the CMHI model predicts that task conditions influence learning. One task condition would be the clarity of the documents. When the causes of historical events are not reported in historical documents, and if the learner lacks the prerequisite declarative knowledge that underlies the standards for causality, then monitoring failures occur and learning outcomes are poor. On the other hand, learners with higher standards for causality, along with some prior knowledge of the domain, sufficient motivation and interest, will most likely engage in goal-setting activities during the second phase of learning to gain better understanding. In the third phase, the CMHI model postulates that self-assessment occurs when explanations are compared to the learners' standards to determine whether they have achieved a deep understanding of the causes that led to the event under investigation. If the outcomes of the inquiry process are uncertain, then a learner returns to the second phase by setting a new goal. If the resulting explanation is certain, then the learner's understanding of why the event occurred is perceived as coherent. When a leaner has formulated a coherent explanation for the event, the learner has mastered that topic and may choose to learn about a different topic or cease studying.

Goal-setting activities refer to when the learner defines the desired learning outcome by choosing a goal in the second phase of learning. The learners set goals based on their monitoring activities, where the learning outcomes are compared to the standards for causality. The CMHI model distinguishes between the following goals: argue in favour of the most likely cause for an event, weigh alternative causes, and anticipate counter-arguments. If the causes of the event are unknown, the learner is more likely to begin the inquiry process by seeking for the most likely cause for the event. If the causes of the event are uncertain, the learner is more likely to weigh alternatives or anticipate counter-arguments.

Control activities are the disciplinary-based practices or strategies used in the context of inquiries into the causes of historical events. A line of inquiry consists of the initial formulation of an historical explanation, and its subsequent revision, as a result of the analysis of information that was obtained from historical documents during learning (van Drie and van Boxtel 2008). Each line of inquiry has a distinct goal. Strategies refer to the way in which information is analyzed by a learner. The CMHI model includes the following strategies that are based on the model of historical reasoning proposed by van Drie and van Boxtel (2008): asking appropriate questions, formulating explanations, evaluating the trustworthiness of sources, using substantive concepts, as well as gathering, corroborating, and contextualizing evidence. The CMHI model extends the model of van Drie and van Boxtel (2008) by stating that lines of inquiries into the causes of historical events are triggered by a goal, and the strategies are used to attain the goal. The CMHI model postulates that lines of inquiries into the causes of historical events occur in the second phase, when the learner reinstates coherence in understanding why the event occurred.

Overall, the CMHI model provides a domain-specific account of SRL wherein learners engage iteratively and adaptively in cognitive and metacognitive processes to make progress in 
understanding why historical events occurred. There is a need for precise definitions of the different types and properties of cognitive activities outlined in models of SRL. In the next section, we define and exemplify the cognitive activities that are outlined in the CMHI model.

The role of conditions, outcomes, and standards in learning through historical inquiry

This section explains the cognitive activities that underlie the learners' ability to monitor their own learning, more specifically, by noticing instances of confusion due to unknown/uncertain causes. We provide an overview of the conditions that mediate the evaluation of outcomes against standards. In support of our claims, we make connections to empirical evidence obtained from the scientific literature.

The CMHI model of SRL maintains that task conditions and cognitive resources influence learning. For example, when a cause of an historical event is not mentioned in a document it may form an obstacle to learning if the learner lacks the relevant prior knowledge (see Gilabert et al. 2005; Linderholm et al. 2000; Vidal-Abarca et al. 2006; Vidal-Abarca et al. 2000). The existing research shows that such conditions, when recognized by learners, are experienced as a form of cognitive disequilibrium or dissonance (Graesser et al. 1996). These experiences are often verbalized as the acknowledgement of confusion, not knowing, gaps in knowledge, or instances of questioning. These instances of confusion can be attributed to knowledge deficits and conflicts (see Otero 2009). For instance, learners experience knowledge deficits when they fail to understand why events occur (Poitras et al. 2012a).

When a learning impasse occurs, confusion often leads to efforts to remedy the situation by engaging in alternate activities or remedial strategies (VanLehn et al. 2003; Graesser et al. 2005; Graesser and Olde 2003). For instance, historians who notice instances of discrepancies while analyzing multiple sources explicitly acknowledge their confusion, express puzzlement or wonder, ask questions, and specify gaps in knowledge, but also analyze sources to make better sense of the information (see Wineburg 1998).

Perhaps one of the most important determinant heuristics used in learning about history is causation (for reviews, see Limón 2002; van Drie and van Boxtel 2008). For instance, historians generate causal inferences through a method referred to as counterfactual reasoning (i.e., "If the preceding event did not happen, would the consequent event have happened?"; see Voss et al. 2000; Voss and Wiley 2006). When there are gaps in causal chains of events, the CMHI model postulates that learners engage in causal reasoning by searching for the causes of historical events.

Students' understanding of causation relies on their grasp of concepts in relation to the time period and the discipline (see Halldén 1997, 1998; Voss and Wiley 1997) which impacts their ability to remember details surrounding an historical event (Rivière et al. 1998). Graduate students in history often formulate historical explanations by comparing different societal conditions and factors (e.g., political, economic, ideological, and so on) depending on the particular historical event under consideration, as opposed to students who are less familiar with history, who tend to attribute the occurrence of an event to the intentions and motives of historical characters (Carretero et al. 1997; Jacott et al. 1998). Undergraduate students also acknowledge the importance of considering multiple causes in explaining historical events (Voss et al. 1998) and have an intuitive understanding of notions in relation to counterfactual reasoning - the importance of reasoning about the multiple causes of historical events as opposed to only single causal factors. Students judged the causes of an historical event as reasonably sufficient to produce the outcome, as well as acknowledging the plausibility of other potential causal factors (i.e., conditions of sufficiency and necessity; Voss et al. 1994, 2000). 
The role of goals in learning through historical inquiry

The CMHI model of SRL outlines several goals that determine how learners use strategies while learning about different historical topics. Goals define the desired outcome of any particular line of inquiry, where an explanation is proposed, argued, and revised through the use of strategies. In order to attain goals, a learner gathers evidence as a means to support or refute a claim. The factual information that underlies this justification is then corroborated by similar information (i.e., strengthened or supported by additional evidence) or discorroborated by different information obtained from historical documents (i.e., weakened or refuted by additional evidence). As a result, the explanation for the event changes as causes become less or more likely. In the CMHI model, we distinguish between arguing in favour of the most likely cause, weighing alternative causes, and anticipating counterarguments.

Arguing in favour of the most likely cause involves both supporting and corroborating a claim in regards to the most likely cause for the occurrence of an event. As an example, the learner first makes a claim: "The most likely cause for the Acadian Deportation ${ }^{1}$ is the fact that the Acadians refused to swear the oath of allegiance." In support of this claim, the learner finds information obtained from the minutes of a council meeting, where Governor Charles Lawrence states that being a loyal British subject requires taking the oath. The fact is then corroborated by similar information found in a letter, as well as one that was written by Acadian citizens, which explains their reasons for refusing to take the oath. The learner would then have attained the goal of outlining an argument in favour of the most likely cause for the event under investigation.

In weighing alternative causes, a learner either rejects or confirms an alternate explanation. In doing so, any cause, excluding the most likely one, is either supported or refuted, as well as corroborated or discorroborated. For instance, a learner might consider other antecedents to the expulsion of Acadians, such as the second most probable cause, which might be Governor Charles Lawrence's discontent towards the Acadians, even though this was a less likely cause to the occurrence of the event. In this case, a learner may have found discorroborating pieces of information that suggested that the Governor felt regret for the situation that Acadians were put in.

The learner anticipates counter-arguments when a claim, in relation to the most likely cause, is refuted and then discorroborated. For example, the learner attempts to anticipate possible critiques that could be raised against their own position. In regards to the refusal to swear the oath claim, a learner might anticipate the following objective:

"The refusal to swear the oath of allegiance is less likely to cause the Acadian Deportation since a history textbook mentioned that the requirement to swear the oath was just a pretext to divert attention away from the lands, property, and livestock that would be seized from the Acadians."

This fact could be either discredited or discorroborated. In discrediting the source, a learner mentions that the information is not credible since it comes from a second hand source. In discorroborating the information, a learner would argue that the Deportation itself cost the government a lot of money. In either case, the objection that is raised in regards to the claim is refuted.

\footnotetext{
${ }^{1}$ The Acadian Deportation refers to the expulsion of the French inhabitants of Nova Scotia from their homeland in 1755. The learners in this example were investigating the causes and contributing factors of this event by explaining why Governor Lawrence gave the order to begin the deportation.
} 
The role of strategies in learning through historical inquiry

The aim of this section is to define and exemplify the constructs pertaining to strategy use that are included in the CMHI model. We integrated existing models of the cognitive activities involved in historical reasoning in order to account for the properties of strategy use (see Carretero et al. 1997; Nokes et al. 2007; van Drie and van Boxtel 2008). In doing so, we distinguish between superordinate and subordinate categories of constructs. Some constructs, particularly argumentative strategies, have additional properties that are coded as appropriate or inappropriate. For example, our research has shown that a learner may report a fact precisely (appropriate strategy use) and justify their explanation implicitly (inappropriate strategy use). We exemplify strategy use by examining data gathered from learners while performing inquiries into the causes of the Acadian Deportation (see Poitras et al. 2012b).

Question-asking is the first strategy of the model of historical reasoning of van Drie and van Boxtel (2008). van Drie et al. (2006) distinguish between explanatory and evaluative questions. We investigate question-asking in the context of reasoning about the causes of historical events. In asking an explanatory question, the learner searches for a singular cause in order to explain an historical event. For example, a learner might ask: "What caused the Acadian Deportation?" In contrast, evaluative questions are when the learner searches for multiple causes. An example of a learner considering the plausibility of more than a single cause is: "What is the most important cause for the Acadian Deportation?"

The next strategy is to formulate an explanation - a provisional answer to the question (van Drie and van Boxtel 2008). Carretero and colleagues (1997) discern between types of causes that are mentioned in any particular explanation. Personalistic explanation is when the learner mentions the influence of the intentions and motives of significant historical figures. For example, the occurrence of an event, such as the Acadian Deportation, can be due to the following: "British Governor Charles Lawrence's discontent towards the Acadians." Political explanation relates to the societal situation immediately prior to the event. An example of a political situation is: "The Acadian deputies and communities refusal to swear the unconditional oath of allegiance." Economic explanation is the financial situation during that time period: "British Governor Charles Lawrence wanted to seize the Acadians land, property, and livestock." Ideological explanation is when the learner mentions the commonly held beliefs of important historical figures. An example of the ideological context is: "The Acadians could become loyal British subjects by assimilating them across the colonies." International policy explanation refers to the global situation. An example of a learner referring to the international context is: "Prevent the Acadians from joining with their enemies in the conflict between the French and British empires."

In sourcing or evaluating the trustworthiness of sources, learners determine whether a source of information provides a reliable account of the event (van Drie and van Boxtel 2008). Nokes and colleagues (2007) classify such evaluations in terms of either the author or document. In evaluating the author, learners may critique such things as the credibility of the author's position, motivation, participation, and so on. In regards to the document, a learner may evaluate the date of production, the document type, and so on. We provide an example below:

"The source is authored by the King's representative/Governor in Nova Scotia who had been in the region for some time and an eye-witness of the events leading up to the expulsion. He was also a direct officer of the King and would be in a position to know exactly what the King's wishes may be with regard to the oath of allegiance, and to execute them on his behalf." 
The example shows a learner evaluating the trustworthiness of the author's position by identifying the credentials of Edward Cornwallis, the author of the document. The learner also looks at the properties of the document and evaluates its trustworthiness by seeing if the document is a first or second-hand source and whether there is any indication of bias. For instance, the learner correctly classifies the document as a primary source in support of its credibility but fails to note the potential source of bias - a first-hand account of the event written from the British's point of view.

The next strategy is gathering evidence to outline an argument for or against an explanation (van Drie and van Boxtel 2008). Nokes and colleagues (2007) distinguish between gathering evidence through a direct quote, general citation, or specific reference. The following example illustrates gathering evidence from a direct quote from a document in support of an explanation for an event:

"Page 171, paragraph 3 states that the King "is not willing that any of his subjects... should be exempted from an entire allegiance." This means that the oath will be a compulsory requirement for everyone in the colonies, regardless of prior exemptions. [...] Thus the French deputies' [sic] refusal to swear the oath seems to have been a factor in their being seen as disloyal which turned the authorities against them and instigated their eventual deportation."

In the first sentence of this example, the learner uses a direct quote as the source of evidence and in fact accurately reported and justified the claim. The learner justified how the information in the quote supported the explanation that the Acadian Deportation was due to Acadians refusing to swear an oath of allegiance to the King.

Learners use corroborating evidence as a strategy to further develop their arguments (van Drie and van Boxtel 2008). Learners corroborate evidence by making connections with both similar and different information. Nokes and colleagues (2007) state that corroborating arguments are made through direct comparison and direct contrast. A direct comparison is when the learner makes a connection between similar information whereas a direct contrast involves selecting different information.

The learner contextualizes evidence by elaborating on the details that surround the event (van Drie and van Boxtel 2008). Contextual information such as awareness of the time or location of the event, the culture or setting, the biography of significant historical figures, historiography, and linguistics all help with developing an argument (Nokes et al. 2007). Historiography refers to the circumstances that surrounded the act of writing or illustrating certain aspects of the event, and its subsequent implications for the reliability of the source. The following example illustrates an instance of showing awareness of the historiography through the analysis of sources of information:

"In English Doc 2, the author uses a condescending tone to address the French deputies and dismisses all their claims as illegitimate e.g. he uses phrases such as "contrary to common sense," which is an insult. The French Doc 1 though not dated seems to use a more conciliatory tone and in French Doc 2, there seems to be an agreement and effort to be subject to the British government. These letters seem to suggest a hardening stance from the British authorities alongside a gradual acquiescence of the French but only to a certain point, that is, they would be subject to the King without pledging total allegiance as this might have caused retaliation from the Native Americans around them." 
The example shows a learner that elaborates on historiography by drawing conclusions based on the tone used by the author of the documents while recording an account of the event.

A final strategy is when a learner uses substantive concepts in relation to historical phenomena, persons, and time periods (van Drie and van Boxtel 2008) that help synthesize and organize information obtained from many sources (Halldén 1997). An example of using concepts in relation to the Acadian Deportation is: "The Seven Year's War is the first global conflict which involved both French and British."

Theoretical perspectives on self-regulated learning: from domain-general to domain-specific perspectives

In the previous section, we have outlined the CMHI model of SRL, a domain-specific account of self-regulating in problem-solving within the domain of history. We will now examine the differences and similarities between the CMHI model of SRL and the IPT model of SRL as proposed by Winne and colleagues (Winne 2001, 2005; Winne and Hadwin 1998, 2008, 2010). In doing so, we claim that the CMHI model of SRL has many similarities to the basic regulatory mechanisms and processes of the IPT model of SRL. However, there are inherent differences in the constituent constructs that are attributed to the relevant knowledge of tasks within a particular discipline.

We will then turn to our argument in favour of examining the domain-specificity of SRL constructs by justifying the following claims. First, the CMHI model stands to account for the onset of historical reasoning by explaining the ability of certain learners to ask questions pertaining to the causes of historical events. Second, the CMHI model captures the ability to monitor certain aspects of historical reasoning, which is an aspect of the trajectory towards competency in the domain of history that has been overlooked in previous studies. Third, the CMHI model is needed to inform the design of pedagogical practices that are necessary to support history learners when learning about the causes of historical events.

\section{A comparison and contrast of domain-general and domain-specific accounts of SRL}

Winne and colleagues outlined the IPT model of SRL in order to characterize how students regulate certain aspects of their learning while studying texts. According to this model, learning occurs in weakly sequenced and recursive phases: (1) task definition, (2) goalsetting and planning, (3) studying tactics, and (4) adaptations. Self-regulated learners first clarify the instructor's expectations as to the time needed to complete the task and the performance criteria as well as search for all available resources. When setting goals, learners plan the steps that must be taken to achieve each goal while learning about the material. To achieve a particular goal, learners use a variety of strategies to study the material, such as managing time and summarizing information. In doing so, learners adapt their own beliefs, motivations, and strategies by altering the manner in which they regulate certain aspects of learning in response to feedback.

COPES processes (conditions, operations, products, evaluations, and standards) are involved in processing information through each phase. Conditions consist of the resources that are available to perform the task, either from the learner, such as the amount of knowledge regarding studying tactics, or the task itself, including the amount of materials, time allotted to study, and so on. Operations refer to the wide range of strategies that are used by self-regulated learners during the studying tactics phase to better assimilate information. Winne (2001) refers to such tactics as SMART processes, and distinguishes between Searching for relevant information, Monitoring one's own understanding, as well as 
Assembling, Rehearsing, and Translating information. These are distinguished from acquired operations that consist of the activation of knowledge in relation to higher-order tactics and strategies. These processes result in cognitive products, or information generated at each phase of learning. Standards refer to the learners' beliefs regarding the requirements that have to be met in order for learning to be deemed a success. Evaluations occur when learners compare the products of a particular phase to the relevant standards in order to make adjustments that are necessary to resolve obstacles to learning.

The IPT model maintains that the products of each phase is monitored against standards, and then controlled as these evaluations update relevant conditions at the task-level (i.e., resources, instructional cues, time, and social context) or at the cognitive-level (i.e., beliefs, dispositions, styles, motivational factors, orientations, knowledge of the domain, task, as well as tactics and strategies). Alternatively, the relevant conditions can be updated directly through the product of each phase or through external evaluations that are made by instructors in relation to task performance. The task and cognitive conditions impact learning by influencing the learners' operations as well as the choice of standards that are used to evaluate the products obtained in each phase of SRL.

The CMHI model is different from the IPT model of SRL in terms of the nature of the constituent constructs that are used to characterize SRL. The CMHI model conceptualizes phases differently from the IPT model of SRL in that each phase describes a distinct state in understanding the event under investigation. Learners' progress through each phase as their understanding of the causes for the event under investigation becomes progressively more coherent. While the notion of phases in the CMHI model characterizes distinct stages in solving a problem, the IPT model relies on the notion of phases to explain distinct products in studying text. The IPT model uses the notion of phases to characterize the different products that result from assemblies of operations that are monitored and controlled by learners. These ensembles of operations are not only distinguished by differences in the resulting products, but also in terms of the sequence in which they are activated all throughout learning. As such, the definition of phases in the CMHI model of SRL refers to the learners' mental representation of the topic, while the IPT model of SRL allows for a broader definition, including, the learners' representation of the task, goals, strategies, and adaptations.

Furthermore, the CMHI model situates the definition of constructs such as operations within the particular domain in question. For instance, the model defines 36 subordinate strategies categorized as 7 superordinate strategies, including asking appropriate questions, formulating an explanation, evaluating the trustworthiness of sources, using concepts, as well as gathering, corroborating, and contextualizing evidence ${ }^{2}$. This stands in stark contrast to the IPT model of SRL, which defines operations by distinguishing between simple (i.e., SMART processes) and acquired tactics and strategies. These operations are typically conceived as text-studying strategies that are applicable across domains, such as summarizing information from text and elaborating on its content (see Greene et al. 2010). Although a disciplinary-based strategy such as contextualizing evidence could be decomposed in terms of simple operations or incorporated as part of acquired tactics and strategies, a unifying framework that clearly delineates the levels and definitions of such operations on the basis of empirical evidence has yet to be outlined.

\footnotetext{
${ }^{2}$ A coding scheme that defines each construct of the CMHI model of SRL is available upon request from the authors of this manuscript. The coding scheme was built by synthesizing existing models in the field of historical reasoning (Carretero et al. 1997; Nokes et al. 2007; van Drie and van Boxtel 2008) and SRL (Winne 2001, 2005; Winne and Hadwin 1998, 2008, 2010).
} 
Although the scope of the CMHI model is limited to the amount of empirical evidence available to support its claims, it is similar to the IPT model of SRL with respect to the regulatory mechanisms that are stipulated to account for SRL, albeit with slight differences in terminology. The CMHI and IPT model both account for the role of self-regulation in learning through information manipulation processes that are metacognitive (monitoring, goal-setting, and control) and cognitive in nature (conditions, standards, outcomes, goals, and strategies). Learning outcomes are compared to standards as the students monitor their progress while studying text and solving problems. Learners engage in remedial activities to control their own learning by setting goals and using strategies to achieve them. In doing so, learning is constrained by relevant conditions, such as the nature of the task characteristics, the motivation and interest of the learner, and the amount of knowledge in relation to the domain and topic.

In summary, the main differences between domain-general and domain-specific accounts of SRL are found in how the constitutent constructs are defined, while the basic processes that underlie self-regulation are maintained in both accounts. The breadth of processes that are accounted for by both models, however, depends on the amount of supporting evidence that can be drawn from the literature. In the case of the CMHI model of SRL, this corresponds to only a subset of all the processes that are accounted for in the IPT model of SRL. In the following sections, we will argue that there are several benefits to conceptualizing the domain-specific aspects of SRL, and that researchers should further study similarities and differences in SRL across several task and domain areas.

\section{Explaining the onset of reasoning and problem-solving in history}

In reasoning about the causes of historical events, students use reasoning tactics to evaluate, analyze, and synthesize information obtained from historical sources (Leinhardt and Young 1996; Seixas 1993; Spoehr and Spoehr 1994; Wineburg 1991). Researchers have only recently begun to examine the different types of questions, and how different historical thinking skills lead to formulating answers (for reviews, see Barton 2008; Levstik 2011). Van Drie and van Boxtel (2008) argue that these questions are critical to initiate historical reasoning and most importantly, why students perform inquiries into the causes of historical events.

Logtenberg et al. (2011) conducted a study that examined the amount and type of questions generated by students while reading three different types of historical texts (i.e., narrative, problematizing, and expository). A hundred and seventy-four high-school students (upper-secondary/pre-university) were assessed on their prior knowledge and interest. Students were most interested in the narrative and problematizing text, which in combination with their amount of prior knowledge, was found to be predictive of the overall amount of questions asked. This finding suggests that more knowledgeable and interested students tend to formulate more questions in regards to an historical topic. Furthermore, students formulated a total of 729 questions (Logtenberg et al. 2011). While $26 \%$ of these questions were categorized as explanative (129), only $4 \%$ were evaluative (28). As an example, an explanatory question might involve asking "What caused the Second World War?" as opposed to an evaluative question, "What is the most important cause for the Second World War?" (van Drie and van Boxtel 2008). van Drie et al. (2006) found that asking explanatory as opposed to evaluative questions leads to less historical thinking. As such, the amount of prior knowledge, interest, as well as task characteristics can all determine the types of questions asked by learners, which subsequently impacts how learners engage in historical thinking skills to formulate an answer. 
The CMHI model allows researchers to formulate testable research hypotheses with the aim of explaining why learners ask historical questions and engage in lines of historical inquiry. Question-asking is preceded by learners' efforts to monitor their own learning in response to obstacles to learning (see Otero 2009; Otero and Graesser 2001). The ability to monitor one's own understanding explains why learners are able to detect instances of confusion that result from information that is either missing or is contradictory in nature.

According to the CMHI model of SRL, information is missing from historical sources when a document fails to mention the causes and contributing factors that led to historical events. The ability to monitor learning by comparing one's own mental representation of the event against standards for causation is essential to detect instances of confusion that result from this learning impasse. Self-regulated learners will be able to monitor their own understanding, set a goal to investigate further, and ask an appropriate question. In these cases, explanatory (Why did the event happen?) or evaluative (What were the most important causes?) questions are considered to be appropriate in terms of addressing the problem (see Van Drie and Van Boxtel 2008). The CMHI model accounts for the ability of learners to monitor their own understanding as resulting from (a) high prior knowledge in relation to the domain and task, (b) low prior knowledge in regards to the topic under investigation, and (c) high interest and motivation towards the topic under investigation. Under these conditions, the CMHI model of SRL predicts that learners are able to ask appropriate questions to investigate the causes of the event under investigation.

\section{Accounting for proficiency in learning about history}

The existing empirical research on proficiency differences in learning about history has compared strategy use across novices and experts (Voss and Wiley 2006). For instance, the ability to corroborate evidence is a strategy that consists of comparing a piece of information against other sources to identify similarities and discrepancies. This skill, also referred to as "intertextual reading", is important in evaluating the credibility of evidence when reading source documents that are unfamiliar. Historians use this strategy to construct and support their own interpretations (Leinhardt and Young 1996; Wineburg 1998) by checking whether an important piece of information is found in other sources before they accept it as being plausible (Wineburg 1991). For instance, historians (1) identify discrepancies with information which was read earlier, (2) note the plausibility of information based on the amount of details found in the account, (3) ask follow-up questions to search further once they identify a discrepancy, and (4) create hypothetical scenarios to explain the discrepancy. In contrast, high-school students often fail to notice discrepancies and seldom look back at previously read documents (Wineburg 1991). Therefore, novice students are more likely to fail to reject factual information in the presence of discorroborating information.

Researchers have alluded to the role of metacognitive monitoring in regards to the ability to become more aware of these inferential processes while learning about an unfamiliar topic. For instance, historians that are unfamiliar with a particular event are aware that their interpretations of textual information are biased by their lack of knowledge in regards to the event under investigation. As such, they engage in intertextual reading strategies such as asking questions, suspending judgements and evaluations, being aware of their affective reactions, and reinstating previously read information in an effort to reconstruct the historical event from information gathered from source documents (Leinhardt and Young 1996; Wineburg 1998).

The CMHI model of SRL stands to provide a framework for researchers to study the role of metacognitive monitoring, and how it mediates the development of expertise in the 
domain of history. Besides the standards of causation against which are compared the outcomes of the inquiry process in the CMHI model of SRL, the SRL literature has a broad range of constructs that could be used for the purposes of studying this phenomena. Meijer and colleagues (2006) found that deliberately pausing and going back in text, while also noting lack of knowledge were important metacognitive monitoring skills used while studying historical texts. In addition, Greene and colleagues (2010) found that questioning oneself, evaluating text content, as well as expressing feelings or judgements of knowing were amongst the most frequent monitoring processes used while studying text. These frameworks of metacognitive monitoring provide useful clues to better characterize expertise and how it develops in solving problems within the domain of history.

Domain-specific models are needed to address instructional challenges in history

The existing empirical evidence suggests that learners often fail to regulate certain aspects of learning (for a review several types of failures, see Azevedo and Feyzi-Behnagh 2011). As an example, Greene and his colleagues (2010) found that high-school students often fail to set learning goals, use appropriate strategies, and monitor their own progress while learning about history. As a result, the students showed modest gains in relation to knowledge about the topic and historical thinking skills. Furthermore, Poitras and colleagues (2012a) investigated undergraduate students' ability to monitor and strategically control their own understanding of why historical events occur. Students who did not receive assistance failed to both (a) notice that historical documents did not report the causes of particular events and (b) formulate tentative explanations. Consequently, students' ability to recall and understand details surrounding the event was mediocre.

Given the challenges faced by learners to engage in SRL, researchers have designed computer-based learning environments to foster different aspects of SRL during learning (for reviews, see Azevedo and Aleven 2013; Devolder et al. 2012; Schraw 2007; Winters et al. 2008). To mention only a few, computer-based learning environments successfully support students to engage in SRL while learning about the human circulatory system (MetaTutor; Azevedo et al. 2010), ecosystems, climate change, and thermoregulation (Betty's Brain; Kinnebrew and Biswas 2011), as well as geometry theorems (Geometry Cognitive Tutor; Koedinger et al. 2009), and medical diagnostic reasoning (Lajoie 2009). Although researchers have made progress in improving instruction about science topics with computer-based learning environments, relatively little is known about the role of SRL in learning about history (see Greene et al. 2010; Meijer et al. 2006). Therefore, there exists a clear need to further study the potential of computer-based learning environments to provide instruction about SRL with the goal of addressing the challenges faced by students while learning about history.

To address this research gap, the CMHI model was used to guide the design of the MetaHistoReasoning tool, a computer-based learning environment that helps learners in the regulation of their learning while performing inquiries into the causes of historical events (Poitras and Lajoie 2013). Preliminary findings from our evaluation of this system suggest that the MetaHistoryReasoning tool supports learners in developing SRL skills that are particular to the domain of history. More specifically, Poitras et al. (2012c) found that the examples of strategy use provided by the system facilitate skill acquisition, but that certain strategies, including gathering, corroborating, and contextualizing evidence, are more difficult to acquire. In addition, learners used skills such as gathering evidence by correctly quoting or paraphrasing factual information, but they often failed to justify how the factual information supported their own claims regarding the causes of the event under investigation. By examining how learners use or misuse domain-specific SRL skills, Poitras and colleagues (2012b) have 
identified several areas to improve instruction. This research has proven informative not only in terms of providing learners with instruction about SRL, but also in designing a better system that is able to adapt instruction to facilitate skill development.

\section{Conclusions and Future Directions}

Current theories of SRL are limited in their ability to disambiguate constructs and processes that pertain to particular tasks, topics, and disciplines (Alexander et al. 2011; Meijer et al. 2006; Veenman et al. 2004). Our theoretical discussion aimed to refine the basic definition of domain-specificity for SRL by distinguishing between three underlying assumptions: (a) certain aspects of self-regulated learning are particular to certain disciplines; (b) learners regulate their learning through an iterative and adaptive process wherein cognitive and metacognitive activities interact with each other; and (c) learning occurs in the context of performing authentic tasks in the relevant discipline.

These basic assumptions are reflected in the constructs and processes of the CMHI model, a domain-specific account of SRL. According to the model, a history learner trying to identify causes of historical events regulates learning while making progress in understanding why events occurred, and this process is characterized through several phases (i.e., lack of understanding why an event occurred, reinstatement of coherence in understanding, and attainment of a coherent understanding). The metacognitive activities involved in making progress in each phase of the inquiry process are modelled as an acquired system of self-instructions (see Veenman 2011; Winne 2010; Winne and Hadwin 2008). Namely, learners regulate their own learning through cognitive (i.e., conditions, standards, outcomes, goals, and strategies) and metacognitive activities (i.e., monitoring, goal-setting, and controlling), which occur in an iterative and adaptive manner.

In order to support the assertions of the proposed model, we presented an argument in favour of the need to model self-regulatory activities that are particular to the discipline of history. We reviewed empirical evidence in several areas in the scientific literature pertaining to self-regulated learning, historical reasoning, and novice-expert differences. The analysis of the evidence suggests that the CMHI model stands to inform educational interventions that provide more suitable instruction, makes an important step in accounting for why learners begin the inquiry process, and captures an overlooked aspect of proficiency in learning about history. In outlining the CMHI model of SRL, several questions remain to be addressed in future research: (1) What is the role of self-regulation in relation to affective and motivational constructs and how it mediates learning through historical inquiry?; (2) What are the different standards that underlie learners' efforts to regulate their own learning while performing inquiries into complex historical topics?

In regards to the first question, the CMHI model maintains that motivation and intention are critical factors that influence learners' efforts to pursue their investigation. Research has shown that learners with high interest towards a historical topic are more likely to ask more questions while studying text (Logtenberg et al. 2011). Little is known in regards to learners' ability to monitor and control their own emotions in this context and the resulting impact that emotional regulation may play in motivation when learners face challenging task conditions. When learners investigate the causes of historical events, the causes are at first unknown, and relevant information might be difficult to find when searching through large amounts of source documents. Learners' may develop feelings of confusion and frustration during such investigations and their ability to persist in their efforts is critical to successful performance. Furthermore, positive emotions, such as the sense of relief that occurs when they find 
information, may stop them from further investigating the event. This is problematic since certain emotional states may lessen efforts to engage in multiple lines of inquiry that are necessary to confirm an explanation with greater confidence, weigh alternative causes, and to anticipate and respond to counter-arguments. The CMHI model should be extended to study meta-affect in historical inquiry and its impact towards learning.

A second area that should be considered in expanding the CMHI model of SRL is the nature of the standards used to evaluate the outcomes of the inquiry process. The CMHI model accounts for evaluating the outcomes of lines of inquiries against standards of causation whereby causation is one method that used by historians to investigate historical phenomena (van Drie and van Boxtel 2008). There are several other methods used by historians when they investigate historical events (see meta-concepts, van Drie and van Boxtel 2008). As an example, the description of processes of historical change involves the distinction of sudden and gradual changes in political, economical, social, and cultural changes. The comparison of historical phenomena consists of the identification of similarities and differences between historical phenomena. The notion of causation could be further extended to the distinction of long term and immediate causes as well as the interrelationship between causes. Finally, the use of sources and the identification of credible and relevant information are also critical to any investigation.

To better understand the nature of disciplinary-based standards, and how they mediate learners' abilities to monitor the outcomes of their inquiries, researchers could study novice-expert differences in self-regulation. Concurrent and retrospective measures of metacognitive activities (monitoring, goal-setting, and controlling) collected with both novices and experts in the context of performing inquiries into complex historical topics may be instrumental in better understanding the role of standards in the CMHI model and how it can be expanded. Researchers may be able to detect such standards through the collection and analysis of think-aloud data that could reveal expert-novice differences in the strategies and explanations used while participants conduct historical inquiries. The identification of the breadth and depth of metacognitive standards used in evaluating the outcomes of inquiries can lead to a better understanding of historical reasoning that would help plot the learning trajectories in this domain of study.

In conclusion, we maintain that the basic assumptions that were formulated in this article can be incorporated into the creation of new models of self-regulatory activities that are involved in learning while performing tasks that are particular to certain disciplines, such as history, medicine, and engineering. Domain-specific models of SRL aim to accurately describe the attributes of learning on the basis of components that make testable predictions in accordance with disciplinary-based practices. In order to characterize the connection between domain-general and domain-specific accounts of SRL, we have compared and contrasted constructs and processes in the different areas and phases outlined by the CMHI model of SRL against the IPT theory of SRL (Winne 2001, 2005; Winne and Hadwin 1998, 2008, 2010).

Although the nature of the theoretical constructs reflects differences that are inherent to the task and domain, the representation of the basic regulatory mechanisms and processes (i.e., IF-THEN production rule system) shares similarities with domain-general accounts of SRL. For instance, the adaptability of learning that characterizes SRL is manifested in both domain-specific and domain-general models as learners being able to shift from setting goals to monitoring their own progress and engaging in remedial strategies. We maintain that characterizing the domain-specificity of SRL stands to not only extend the relevance of this theory to educational researchers in other areas, but make important advances towards creating a unifying framework of SRL by abstracting the common SRL principles that are found across different domains and tasks. 


\section{References}

Alexander, P. A., Dinsmore, D. L., Parkinson, M. M., \& Winters, F. I. (2011). Self-regulated learning in academic domains. In B. Zimmerman \& D. Schunk (Eds.), Handbook of self-regulation of learning and performance. New York: Routledge.

Azevedo, R. (2009). Theoretical, methodological, and analytical challenges in the research on metacognition and self-regulation: a commentary. Metacognition and Learning, 4(1), 87-95.

Azevedo, R., \& Aleven, V. (Eds.). (2013). International handbook of metacognition and learning technologies. Berlin: Springer.

Azevedo, R., \& Feyzi-Behnagh, R. (2011). Dysregulated learning with advanced learning technologies. Journal of e-Learning and Knowledge Society, 7(2), 9-18.

Azevedo, R., Johnson, A., Chauncey, A., \& Burkett, C. (2010). Self-regulated learning with MetaTutor: Advancing the science of learning with metacognitive tools. In M. Khine \& I. M. Saleh (Eds.), New science of learning: Cognition, computers and collaboration in education (pp. 225-243). New York: Springer.

Baker, L., \& Brown, A. L. (1984). Metacognitive skills and reading. In P. D. Pearson, R. Barr, M. L. Kamil, \& P. Mosenthal (Eds.), Handbook of reading research (pp. 353-394). White Plains: Longman.

Barton, K. C. (2008). Students' ideas about history. In L. S. Levstik \& C. Tyson (Eds.), Handbook of research on social studies (pp. 239-258). New York: Erlbaum.

Boekaerts, M., Pintrich, P. R., \& Zeidner, M. (Eds.). (2000). Handbook of self-regulation. San Diego: Academic.

Bong, M. (2001). Between- and within-domain relations of academic motivation among middle and high school students: self-efficacy, task-value, and achievement goals. Journal of Educational Psychology, 93(1), 23-34.

Brown, A. L. (1978). Knowing when, where, and how to remember: A problem of metacognition. In R. Glaser (Ed.), Advances in instructional psychology, vol. 1 (pp. 77-165). Hillsdale: Lawrence Erlbaum Associates Inc.

Butler, D. L., \& Winne, P. H. (1995). Feedback and self-regulated learning: a theoretical synthesis. Review of Educational Research, 65(3), 245-281.

Carretero, M., López-Manjón, A., \& Jacott, L. (1997). Explaining historical events. International Journal of Educational Research, 27(3), 245-253.

Corno, L., \& Mandinach, E. (1983). The role of cognitive engagement in classroom learning and motivation. Educational Psychologist, 18, 88-108.

Devolder, A., van Braak, J., \& Tondeur, J. (2012). Supporting self-regulated learning in computer-based learning environments: systematic review of effects of scaffolding in the domain of science education. Journal of Computer Assisted Learning, 28(6), 499-588.

Dinsmore, D., Alexander, P., \& Loughlin, S. (2008). Focusing the conceptual lens on metacognition, selfregulation, and self-regulated learning. Educational Psychology Review, 20(4), 391-409.

Efklides, A. (2008). Metacognition: defining its facets and levels of functioning in relation to self-regulation and co-regulation. European Psychologist, 13, 277-287.

Efklides, A. (2009). The role of metacognitive experiences in the learning process. Psicothema, 21(1), 76-82.

Flavell, J. H. (1976). Metacognitive aspects of problem solving. In L. B. Resnick (Ed.), The nature of intelligence (pp. 231-236). Hillsdale: Erlbaum.

Fox, E., \& Riconscente, M. M. (2008). Metacognition and self-regulation in James, Piaget, and Vygotsky. Educational Psychology Review, 20(4), 373-389.

Gilabert, R., Martínez, G., \& Vidal-Abarca, E. (2005). Some good texts are always better: text revision to foster inferences of readers with high and low prior background knowledge. Learning and Instruction, $15(1), 45-68$.

Goetz, T., Cronjaeger, H., Frenzel, A., Lüdtke, O., \& Hall, N. C. (2010). Academic self-concept and emotion relations: domain specificity and age effects. Contemporary Educational Psychology, 35, 44-58.

Graesser, A. C., \& Olde, B. A. (2003). How does one know whether a person understands a device? The quality of the questions the person asks when the device breaks down. Journal of Educational Psychology, 95(3), 524-536.

Graesser, A. C., Baggett, W., \& Williams, K. (1996). Question-driven explanatory reasoning. Applied Cognitive Psychology, 10, 17-32.

Graesser, A. C., Lu, S., Olde, B. A., Cooper-Pye, E., \& Whitten, S. (2005). Question asking and eye tracking during cognitive disequilibrium: comprehending illustrated texts on devices when the devices break down. Memory and Cognition, 33, 1235-1247.

Greene, J. A., Bolick, C. M., \& Robertson, J. (2010). Fostering historical knowledge and thinking skills using hypermedia learning environments: the role of self-regulated learning. Computers \& Education, 54, 230-243.

Halldén, O. (1997). Conceptual change and the learning of history. International Journal of Educational Research, 27, 201-210. 
Halldén, O. (1998). On reasoning in history. In J. F. Voss \& M. Carretero (Eds.), Learning and reasoning in history. International review of history education, vol. 2 (pp. 272-278). London: Woburn.

Jacott, L., López-Manjón, A., \& Carretero, M. (1998). Generating explanations in history. In J. F. Voss \& M. Carretero (Eds.), Learning and reasoning in history. International review of history education, vol. 2 (pp. 294-306). London: Woburn.

Kinnebrew, J. S., \& Biswas, G. (2011). Modeling and measuring self-regulated learning in teachable agent environments. Journal of e-Learning and Knowledge Society, 7(2), 19-35.

Koedinger, K., Aleven, V., Roll, I., \& Baker, R. (2009). In vivo experiments on whether supporting metacognition in intelligent tutoring systems yields robust learning. In A. Graesser \& D. Hacker (Eds.), Handbook of Metacognition in Education (pp. 383-412). New York: Routledge

Kuhn, D. (1999). Metacognitive development. In L. Balter \& C. TamisLeMonda (Eds.), Child psychology: A handbook of contemporary issues (pp. 259-286). Philadelphia: Psychology Press.

Lajoie, S. P. (2009). Developing professional expertise with a cognitive apprenticeship model: examples from avionics and medicine. In K. A. Ericsson (Ed.), Development of professional expertise: Toward measurement of expert performance and design of optimal learning environments (pp. 61-83). Cambridge: Cambridge University Press.

Leinhardt, G. (1997). Instructional explanations in history. International Journal of Educational Research, $27(3), 221-232$.

Leinhardt, G., \& Young, K. M. (1996). Two texts, three readers: distance and expertise in reading history. Cognition and Instruction, 14, 441-486.

Levstik, L. S. (2011). Learning history. In R. E. Mayer \& P. A. Alexander (Eds.), Handbook of research on learning and instruction (pp. 108-126). New York: Routledge.

Limón, M. (2002). Conceptual change in history. In M. Limón \& L. Mason (Eds.), Reconsidering conceptual change. Issues in theory and practice (pp. 259-289). Dordrecht: Kluwer.

Linderholm, T., Everson, M., van den Broek, P., Mischinski, M., Crittenden, A., \& Samuels, J. (2000). Effects of causal text revisions on more- and less-skilled readers' comprehension of easy and difficult texts. Cognition and Instruction, 18, 525-556.

Logtenberg, A., van Boxtel, C., \& van Hout-Wolters, B. (2011). Stimulating situational interest and student questioning through three types of historical introductory texts. European Journal of Psychology of Education, 26(2), 179-198.

Meijer, J., Veenman, M. V. J., \& van Hout-Wolters, B. H. A. M. (2006). Metacognitive activities in text-studying and problem-solving: development of a taxonomy. Educational Research and Education, 12(3), 209-237.

Metcalfe, J. (2009). Metacognitive judgements and control of study. Current Directions in Psychological Science, 18, 159-163.

Neisser, U. (1967). Cognitive psychology. New York: Appleton.

Nokes, J. D., Dole, J. A., \& Hacker, D. J. (2007). Teaching high school students to use heuristics while reading historical texts. Journal of Educational Psychology, 99(3), 492-504.

Otero, J. (2009). Question generation and anomaly detection in texts. In D. Hacker, J. Dunlosky, \& A. Graesser (Eds.), Handbook of metacognition in education (pp. 47-59). New York: Routledge.

Otero, J., \& Graesser, A. C. (2001). PREG: elements of a model of question asking. Cognition and Instruction, 19, 143-175.

Pintrich, P. R. (2000). Multiple goals, multiple pathways: the role of goal orientations in learning and achievement. Journal of Educational Psychology, 92, 544-555.

Pintrich, P. R. (2004). A conceptual framework for assessing motivation and self-regulated learning in college students. Educational Psychology Review, 16(4), 385-407.

Pintrich, P. R., Smith, D. A., Garcia, T., \& McKeachie, W. J. (1991). A manual for the use of the Motivated Strategies for Learning Questionnaire (MSLQ). Ann Arbor: University of Michigan National Center for Research to Improve Postsecondary Teaching and Learning.

Pintrich, P. R., Smith, D. A., Garcia, T., \& McKeachie, W. J. (1993). Reliability and predictive validity of the Motivation Strategies for Learning Questionnaire (MSLQ). Educational and Psychological Measurement, 53, 801-813.

Poitras, E. G., \& Lajoie, S. P. (2013). A three-pronged approach to the design of technology-rich learning environments. In R. Atkinson (Ed.), Learning environments: Technologies, challenges and impact assessment. Hauppauge: Nova Science Publishers, Inc.

Poitras, E. G., Lajoie, S. P., \& Hong, Y.-J. (2012a). The design of technology-rich learning environments as metacognitive tools in history education. Instructional Science, 40(6), 1033-1061. doi:10.1007/s11251011-9194-1.

Poitras, E. G., Lajoie, S. P., \& Hong, Y.-J. (2012b). Learning through historical inquiry with the MetaHistoReasoning tool. In Proceedings of the 40th Annual Meeting of the Canadian Society for the Study of Education. Waterloo, Canada. 
Poitras, E. G., Lajoie, S. P., \& Hong, Y.-J. (2012c). Using the MetaHistoReasoning tool Training Module to facilitate the acquisition of domain-specific metacognitive strategies. In S. A. Cerri, W. J. Clancey, G. Papadourakis, K. Panourgia (Eds.), Proceedings of the 11th International Conference on Intelligent Tutoring Systems (pp. 511-516). Crete, Greece. doi:10.1007/978-3-642-30950-2_66.

Rivière, A., Núnez, M., Barquero, B., \& Fontela, F. (1998). Influence of intentional and personal factors in recalling historical texts: A developmental perspective. In J. F. Voss \& M. Carretero (Eds.), Learning and reasoning in history. International review of history education, vol. 2 (pp. 214-226). London: Woburn.

Schraw, G. (2006). Knowledge: Structures and processes. In P. Alexander \& P. Winne (Eds.), Handbook of educational psychology (2nd ed., pp. 245-264). San Diego: Academic.

Schraw, G. (2007). The use of computer-based environments for understanding and improving self-regulation. Metacognition and Learning, 2, 169-176.

Schraw, G., \& Moshman, D. (1995). Metacognitive theories. Educational Psychology Review, 7, 351-371.

Schunk, D. H. (2005). Self-regulated learning: the educational legacy of Paul R. Pintrich. Educational Psychologist, 40, 85-94.

Seixas, P. (1993). The community of inquiry as a basis for knowledge and learning: the case of history. American Educational Research Journal, 30(2), 305-324.

Shanahan, C. (2009). Disciplinary comprehension. In S. Israel \& G. Duffy (Eds.), Handbook of research on reading comprehension (pp. 240-260). New York \& London: Routledge.

Spoehr, K. T., \& Spoehr, L. W. (1994). Learning to think historically. Educational Psychologist, 29(2), 71-77.

Van der Stel, M., \& Veenman, M. V. J. (2010). Development of metacognitive skillfulness: a longitudinal study. Learning and Individual Differences, 20, 220-224.

van Drie, J., \& van Boxtel, C. (2008). Historical reasoning: towards a framework for analyzing students' reasoning about the past. Educational Psychology Review, 20(2), 87-110.

van Drie, J., van Boxtel, C., \& van der Linden, J. L. (2006). Historical reasoning in a computer-supported collaborative learning environment. In A. M. O’Donnell, C. E. Hmelo-Silver, \& G. Erkens (Eds.), Collaborative learning, reasoning, and technology (pp. 265-296). Mahwah: Erlbaum.

VanLehn, K., Siler, S., Murray, C., Yamauchi, T., \& Baggett, W. B. (2003). Human tutoring. Why do only some events cause learning? Cognition and Instruction, 21(3), 209-249.

Veenman, M. V. J. (2005). The assessment of metacognitive skills: What can be learned from multi-method designs? In C. Artelt \& B. Moschner (Eds.), Lernstrategien und Metakognition: Implikationen für Forschung und Praxis. Berlin: Waxmann.

Veenman, M. V. J. (2011). Learning to self-monitor and self-regulate. In R. Mayer \& P. Alexander (Eds.), Handbook of research on learning and instruction (pp. 197-218). New York: Routledge.

Veenman, M. V. J. (2012). Metacognition in science education: Definitions, constituents, and their intricate relation to cognition. In A. Zohar \& Y. J. Dori (Eds.), Metacognition in science education: Trends in current research, vol. 40 (pp. 21-36). Netherlands: Springer.

Veenman, M. V. J., Wilhelm, P., \& Beishuizen, J. J. (2004). The relation between intellectual and metacognitive skills from a developmental perspective. Learning and Instruction, 14, 89-109.

Veenman, M. V. J., van Hout-Wolters, B. H. A. M., \& Afflerbach, P. (2006). Metacognition and learning: conceptual and methodological considerations. Metacognition and Learning, 1(1), 3-14.

Vidal-Abarca, E., Martínez, T., \& Gilabert, R. (2000). Two procedures to improve instructional text: effects on memory and learning. Journal of Educational Psychology, 92, 1-10.

Vidal-Abarca, E., Gilabert, R., Gil, L., \& Martínez, T. (2006). How to make good texts for learning: Reviewing text revision research. In A. V. Mitel (Ed.), Focus on educational psychology. New York: Nova.

Voss, J. F., \& Wiley, J. (1997). Developing understanding while writing essays in history. International Journal of Educational Research, 27(3), 255-265.

Voss, J. F., \& Wiley, J. (2006). Expertise in history. In K. A. Ericsson, N. Charness, P. Feltovich, \& R. R. Hoffman (Eds.), The Cambridge handbook of expertise and expert performance (pp. 1746-2424). Cambridge: Cambridge University Press.

Voss, J. F., Carretero, M., Kennet, J., \& Silfies, L. N. (1994). The collapse of the Soviet Union: A case study in causal reasoning. In J. F. Voss \& M. Carretero (Eds.), Cognitive and instructional processes in history and the social sciences (pp. 403-429). Hillsdale: Erlbaum.

Voss, J. F., Wiley, J., \& Kennet, J. (1998). Student perceptions of history and historical concepts. In J. F. Voss \& M. Carretero (Eds.), International review of history education. Learning and reasoning in history, vol. 2 (pp. 307-330). Portland: Woburn Press.

Voss, J. F., Ciarrochi, J., \& Carretero, M. (2000). Causality in history: On the "intuitive" understanding of the concepts of sufficiency and necessity. In J. F. Voss \& M. Carretero (Eds.), Learning and reasoning in history: International review of history education, vol. 2 (pp. 199-213). London: Woburn.

Wineburg, S. S. (1991). Historical problem solving: a study of the cognitive processes used in the evaluation of documentary and pictorial evidence. Journal of Educational Psychology, 83(1), 73-87. 
Wineburg, S. S. (1998). Reading Abraham Lincoln: an expert/expert study in the interpretation of historical texts. Cognitive Science, 22(3), 319-346.

Winne, P. H. (2001). Self-regulated learning viewed from models of information processing. In B. J. Zimmerman \& D. H. Schunk (Eds.), Self-regulated learning and academic achievement: Theoretical perspectives (2nd ed., pp. 153-189). Mahwah: Lawrence Erlbaum.

Winne, P. H. (2005). A perspective on state-of-the-art research on self-regulated learning. Instructional Science, 33, 559-565.

Winne, P. H. (2010). Improving measurements of self-regulated learning. Educational Psychologist, 45(4), $267-276$

Winne, P. H., \& Hadwin, A. (1998). Studying as self-regulated learning. In D. J. Hacker, J. Dunlosky, \& A. Graesser (Eds.), Metacognition in educational theory and practice (pp. 277-304). Hillsdale: Erlbaum.

Winne, P. H., \& Hadwin, A. F. (2008). The weave of motivation and self-regulated learning. In D. H. Schunk \& B. J. Zimmerman (Eds.), Motivation and self-regulated learning: Theory, research, and applications (pp. 297-314). Mahwah: Lawrence Erlbaum Associates.

Winne, P. H., \& Hadwin, A. F. (2010). Self-regulated learning and sociocognitive theory. In P. Peterson, E. Baker, \& B. McGraw (Eds.), International encyclopedia of education, vol. 5 (pp. 503-508). Amsterdam: Elsevier.

Winne, P. H., \& Perry, N. E. (2000). Measuring self-regulated learning. In M. Boekaerts, P. R. Pintrich, \& M. Zeidner (Eds.), Handbook of self-regulation (pp. 531-566). San Diego: Academic.

Winne, P. H., Jamieson-Noel, D. L., \& Muis, K. (2002). Methodological issues and advances in researching tactics, strategies, and self-regulated learning. In M. L. Maehr \& P. R. Pintrich (Eds.), Advances in motivation and achievement, vol. 12. Greenwich: JAI Press.

Winters, F., Greene, J., \& Costich, C. (2008). Self-regulation of learning within computer-based learning environments: a critical analysis. Educational Psychology Review, 20, 429-444.

Zanobini, M., \& Usai, C. (2002). Domain-specific self-concept and achievement motivation in the transition from primary to low middle school. Educational Psychology: An International Journal of Experimental Educational Psychology, 22(2), 203-217.

Zimmerman, B. J. (1989). Models of self-regulated learning and academic achievement. In B. J. Zimmerman \& D. H. Schunk (Eds.), Self-regulated learning and academic achievement. New York: Springer.

Zimmerman, B. J. (2000). Attainment of self-regulation: A social cognitive perspective. In M. Boekaerts, P. R. Pintrich, \& M. Zeidner (Eds.), Handbook of self-regulation (pp. 13-39). San Diego: Academic.

Zimmerman, B. J. (2001). Achieving academic excellence: A self-regulatory perspective. In M. Ferrari (Ed.), The pursuit of excellence through education (pp. 85-110). Mahwah: Erlbaum.

Zimmerman, B. J. (2006). Development and adaptation of expertise: The role of self-regulatory processes and beliefs. In K. A. Ericsson, N. Charness, P. J. Feltovich, \& R. R. Hoffman (Eds.), The Cambridge handbook of expertise and expert performance (pp. 705-722). New York: Cambridge University Press.

Zimmerman, B. J. (2008). Investigating self-regulation and motivation: historical background, methodological developments, and future prospects. American Educational Research Journal, 45(1), 166-183.

Zimmerman, B., \& Schunk, D. (Eds.). (2011). Handbook of self-regulation of learning and performance. New York: Routledge. 